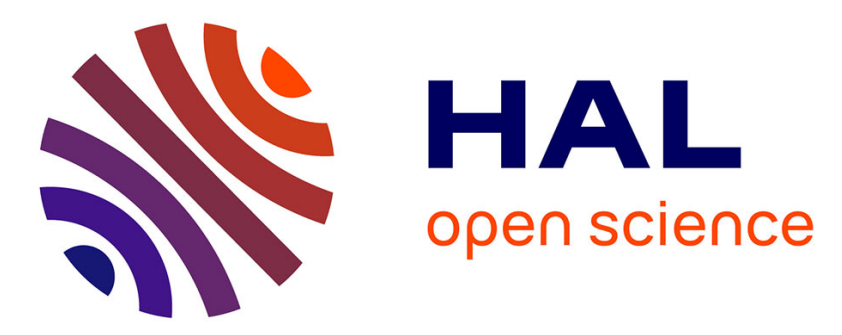

\title{
Alloparental care in the sea: Brood parasitism and adoption within and between two species of coral reef Altrichthys damselfish?
}

Juliette Tariel, Gary Longo, Angela Quiros, Nicole L Crane, Kimberly Tenggardjaja, Alexis Jackson, Bruce E Lyon, Giacomo Bernardi

\section{To cite this version:}

Juliette Tariel, Gary Longo, Angela Quiros, Nicole L Crane, Kimberly Tenggardjaja, et al.. Alloparental care in the sea: Brood parasitism and adoption within and between two species of coral reef Altrichthys damselfish?. Molecular Ecology, 2019, 28 (20), pp.4680-4691. 10.1111/mec.15243 . hal-03353935

\section{HAL Id: hal-03353935 \\ https://hal.science/hal-03353935}

Submitted on 24 Sep 2021

HAL is a multi-disciplinary open access archive for the deposit and dissemination of scientific research documents, whether they are published or not. The documents may come from teaching and research institutions in France or abroad, or from public or private research centers.
L'archive ouverte pluridisciplinaire HAL, est destinée au dépôt et à la diffusion de documents scientifiques de niveau recherche, publiés ou non, émanant des établissements d'enseignement et de recherche français ou étrangers, des laboratoires publics ou privés. 


\section{Alloparental care in the sea: Brood parasitism and adoption within and between two species of coral reef Altrichthys damselfish?}

Juliette Tariel ${ }^{1}$, Gary Londo ${ }^{1}$, Angela Quiros ${ }^{1}$, Nicole L. Crane ${ }^{2}$, Kimberly Tenggardjaja ${ }^{1}$, Alexis Jackson ${ }^{1,3}$, Bruce E. Lyon ${ }^{1}$, Giacomo Bernardi ${ }^{*}$

${ }^{1}$ Department of Ecology and Evolutionary Biology, University of California Santa Cruz, Santa Cruz, CA, USA

${ }^{2}$ Department of Biology, Cabrillo College, Aptos, CA, USA

3The Nature Conservancy, San Francisco, CA, USA

*Corresponding author: bernardi@ucsc.edu

This is the peer reviewed version of the following article: Tariel, J., G. Longo, A. Quiros, N. L. Crane, K. Tenggardjaja, A. Jackson, B. E. Lyon et G. Bernardi. 2019. Alloparental care in the sea: Brood parasitism and adoption within and between two species of coral reef Altrichthys damselfish? Molecular Ecology 28:4680-4691. doi: 10.1111/mec.15243, which has been published in final form at https://doi.org/10.1111/mec.15243.

This article may be used for non-commercial purposes in accordance with Wiley Terms and Conditions for Use of Self-Archived Versions. This article may not be enhanced, enriched or otherwise transformed into a derivative work, without express permission from Wiley or by statutory rights under applicable legislation. Copyright notices must not be removed, obscured or modified. The article must be linked to Wiley's version of record on Wiley Online Library and any embedding, framing or otherwise making available the article or pages thereof by third parties from platforms, services and websites other than Wiley Online Library must be prohibited. 


\section{Abstract}

The evolution of parental care opens the door for the evolution of brood parasitic strategies that allow individuals to gain the benefits of parental care without paying the costs. Here we provide the first documentation for alloparental care in coral reef fish and we discuss why these patterns may reflect conspecific and interspecific brood parasitism. Species-specific barcodes revealed the existence of low levels (3.5\% of all offspring) of mixed interspecific broods, mostly juvenile Amblyglyphidodon batunai and Pomacentrus smithi damselfish in Altrichthys broods. A separate analysis of conspecific parentage based on microsatellite markers revealed that mixed parentage broods are common in both species, and the genetic patterns are consistent with two different modes of conspecific brood parasitism, although further studies are required to determine the specific mechanisms responsible for these mixed parentage broods. While many broods had offspring from multiple parasites, in many cases a given brood contained only a single foreign offspring, perhaps a consequence of the movement of lone juveniles between nests. In other cases, broods contained large numbers of putative parasitic offspring from the same parents and we propose that these are more likely to be cases where parasitic adults laid a large number of eggs in the host nest than the result of movements of large numbers of offspring from a single brood after hatching. The evidence that these genetic patterns reflect adaptive brood parasitism, as well as possible costs and benefits of parasitism to hosts and parasites, are discussed.

Keywords: Altrichthys, behavior/social evolution, brood parasitism, damselfish

\section{Introduction}

The independent evolution of parental care in diverse taxa attests to the fitness benefits of providing care to offspring (Clutton-Brock, 1991; Gross, 2005; Royle, Smiseth, \& Kolliker, 2012). However, parental care also comes with costs, including lost opportunities for additional reproduction plus a reduced future survival or reproduction due to the price of investing in current offspring (Trivers, 1972; Williams, 1966). In several taxonomic groups the evolution of parental care has been followed by the evolution of various forms of reproductive parasitism-reproductive strategies that allow individuals to gain the benefits of parental care without paying the costs. Depending on the taxonomic group, the 
stage of reproduction at which the reproductive parasitism occurs, and how the mixed broods arise, these forms of reproductive parasitism have been called different things: brood parasitism, egg dumping, brood amalgamation, adoption, kidnapping of offspring or, most broadly, alloparental care (Andersson, 1984; Eadie, Kehoe, \& Nudds, 1988; Wisenden, 1999).

Alloparental care occurs when individuals provide parental care for offspring other than their own biological offspring. One key distinction between brood parasitism and other forms of alloparental care is whether the putative reproductive parasite provides subsequent parental care to its offspring. For example, nonparasitic forms of alloparental care include cooperative or social breeding where groups of parents reproduce socially or where nonbreeding helpers assist. In contrast, brood parasites donate eggs or offspring to the broods of others but provide no subsequent parental care-all parental care is provided by the host individuals. Two considerations make this otherwise clear distinction between parasitism and cooperative forms of alloparental care somewhat murky and, as a result, there is no universal agreement as to what falls under the label of brood parasitism. First, mixed parentage broods sometimes result from adoption of offspring after hatching and, in some cases, the adoption could be driven by the parasitic offspring rather than the adult parasite. Some consider these as examples of brood parasitism (Eadie et al., 1988) while others might not. Second, while the term parasitism implies a cost to hosts, providing care to other offspring is not always costly to hosts and, in some cases, may even provide a benefit (Andersson, 1984; Canestrari et al., 2014; Lyon \& Eadie, 2008). The term brood parasitism is generally used to describe the reproductive strategy where adults deposit their eggs or offspring into the nests or broods of hosts, irrespective of costs to those hosts (e.g. Andersson, 1984; Lyon \& Eadie, 2004, 2008). We use this terminology here and also note that it is important to understand the mechanisms by which these forms of alloparental care occur.

Brood parasitism and related forms of alloparental care have been documented in diverse groups, including birds (Davies, 2000; Lyon \& Eadie, 2008; Rothstein, 1990), fish (Sato, 1986), amphibians (Brown, Twomey, Morales, \& Summers, 2008) and arthropods, mostly insects (Boulton \& Polis, 2002; Holldobler \& Wilson, 1990). The specific parental benefits parasites gain by having their offspring raised by others varies depending on taxonomic 
group, but invariably involves the provisioning of some costly form of care to offspring, such as nourishment, warmth or protection from predators (Trivers, 1972; Williams, 1966). In most cases brood parasitism is a reproductive strategy pursued by the adult parasites, but in some related behaviours such as adoption, the reproductive parasitism might result from the behaviours of the adopted offspring. However, there are also examples where the adult parasites facilitate the adoption of their offspring: some female ducks take their ducklings into the territories of other females that then adopt the ducklings (Eadie \& Lyon, 1998).

In some cases, brood parasitism involves parasitism of conspecifics (conspecific brood parasitism, CBP), which by necessity is a facultative strategy because there must be conspecific hosts to parasitize. Many brood parasites lay eggs in the nests of other species (interspecific brood parasitism, IBP), and in many cases the parasites have evolved to become obligate brood parasites where the entire species is dependent on hosts of other species for successful reproduction. Brood parasitism has been most widely documented and studied in birds and insects, so in these two taxa we have a better understanding in terms of why it occurs and how specifically brood parasites gain from parasitism. The evolutionary relationships between the two main forms of parasitism-conspecific and interspecific brood parasitism - have also been studied. This evolutionary relationship is fairly well understood in insects (interspecific parasites often evolve from close relatives; Buschinger, 1986, 2009) but in birds the picture is far less clear and debated (Kruger \& Pauli, 2018; Lyon \& Eadie, 1991; Yom-Tov \& Geffen, 2006).

Brood parasitism has also been observed in fishes, where IBP, easier to identify, has been studied more frequently (Avise, Jones, Walker, \& DeWoody, 2002; Dierkes, Taborsky, \& Kohler, 1999; Taborsky, 2001). The best-known example is found in Lake Tanganyika, where the cuckoo catfish, Synodontis multipunctatus, is an obligate brood parasite of different species of mouth-brooding Trophein cichlids (Blažek et al., 2018; Sato, 1986). IBP has been studied in both freshwater and marine substrate spawners, including many species of Cyprinid minnows that spawn in the nests of other species (Baba, Nagata, \& Yamagishi, 1989; Johnston, 1994) as well as one marine species, the spinynose sculpin, Aemichthys, which spawns in buffalo sculpin Enophrys nests (Kent, Fisher, \& Marliave, 2011). In contrast, CBP in fishes has rarely been documented. In cichlids, egg stealing and 
brood adoption was shown to enhance the protection of a clutch from predators via dilution of eggs, rather than an attempt at parasitizing parental care (Mrowka, 1987a, 1987b; Wisenden, Keenleyside, Wisenden, \& Keenleyside, 1992).

Brood parasitism has not yet been reported in coral reef fishes, perhaps not surprisingly given their reproductive biology. Indeed, the majority of marine fishes exhibit a bipartite life history, with a sedentary adult stage and a dispersive pelagic larval stage (Leis, 1991). Most families (57) are broadcast spawners, where gametes are released in the pelagic environment, thus lacking parental care altogether. In contrast, for those families (14) that are substrate spawners with demersal eggs, parental care is relatively common (Barlow, 1981; Leis, 1991). Such parental care, however, is usually restricted to the very early life stages that typically last only a few days (egg to hatching stage), for example tending, fanning and guarding eggs against predators in clownfishes (genera Amphiprion and Premnas) (Fautin \& Allen, 1997). Indeed, after hatching, offspring become pelagic and remain in the water column for days to weeks. Given this pattern of reproduction, coral reef fishes have few opportunities to engage in brood parasitism.

In damselfishes (Pomacentridae), a family of substrate spawners that includes $\sim 380$ species that are mostly restricted to coral reefs, four closely related species lack a pelagic larval stage (apelagic species): the widespread spiny damselfish, Acanthochromis polyacanthus, and three species in the genus Altrichthys, a genus restricted to the Calamian Archipelago, Philippines (Allen, 1999; Bernardi, 2011; Bernardi, Crane, Longo, \& Quiros, 2017; Bernardi, Longo, \& Quiros, 2017). These species are unique because, unlike most coral reef fishes, parents guard their brood for several weeks after hatching (biparental care system), until the offspring are large enough to escape predation (Allen, 1999; Bernardi, 2011; Bernardi, Crane, et al., 2017; Bernardi, Longo, et al., 2017; Kavanagh, 2000; Robertson, 1973). In the Great Barrier Reef, the cost of parental care in Acanthochromis polyacanthus has been shown to be high (Jordan, Herbert-Read, \& Ward, 2013). Indeed, parents aggressively defend their offspring and also partially feed them with the mucus produced by their skin (glancing behaviour) (Jordan et al., 2013; Kavanagh, 1998; Noakes, 1979; Robertson, 1973). Parents might also transfer important microbial symbionts to their offspring at that stage, as was shown in Discus cichlids (genus Symphysodon) (Sylvain \& Derome, 2017). Occasionally, broods suddenly increase in size 
(number of offspring), and these jumps were interpreted as potential conspecific brood parasitism (Jordan et al., 2013; Thresher, 1985a, 1985b). Yet no genetic analysis was performed to ascertain that brood parasitism was actually present.

In this study, we focused on the two most abundant species of Altrichthys in the Calamian Archipelago, Philippines, A. azurelineatus and A. curatus (Allen, 1999; Bernardi, Crane, et al., 2017; Bernardi, Longo, et al., 2017). Nests are laid deep inside the base of corals, where they cannot be observed directly. Both parents guard the nest and the resulting offspring after hatching. The nest is only guarded by the two parents, and we did not observe any additional satellite adults. Here, we report the occurrence of mixed parentage broods that we propose probably represent both IBP and CBP in Altrichthys. In a previous study in the Calamian Archipelago, where we observed 391 nests of A. azurelineatus and A. curatus (Bernardi, Crane, et al., 2017; Bernardi, Longo, et al., 2017), we noticed that some offspring looked different from most individuals, raising the question of whether brood parasitism was occurring. We now use a genotyping approach to investigate whether brood parasitism actually occurs in either of these two species.

There are two important considerations for studies that use genetic evidence alone to ascertain brood parasitism: (a) errors that come from false assignment or incorrectly sampling broods and (b) even with correct assignment and family sampling, correctly interpreting the biological mechanism that generated the observed genetic patterns. For the first issue, both false family assignment and inadvertent sampling of multiple broods would lead to genetic information that falsely indicates broods that are composed of offspring from more than one set of parents, a pattern consistent with brood parasitism.

The second issue concerns how to correctly interpret the biological mechanism that produces the genetic pattern of broods of mixed parentage. Above we discussed the two basic forms of alloparental care associated with mixed parentage broods: here we are concerned with the subset where a mixed parentage brood is tended by only one set of parents. Wisenden (1999) provides an excellent overview of the mechanisms that can lead to these types of mixed parentage clutches and broods in fishes, while Eadie et al. (1988) and Lyon and Eadie (2008) outline these mechanisms for birds. Five mechanisms can produce broods of offspring of genetic mixed parentage tended by only a subset of parents with offspring in the brood and, depending on the definition of brood parasitism used, 
only the first or two of these are examples of brood parasitism. (a) Brood parasitism by adult brood parasites: a female (or a pair) lays eggs in the nest of another female (or pair in biparental species). (b) Post-hatching adoption: the offspring of one female (or pair) get themselves adopted, either by themselves or with assistance from their parents; such adoptions could be either parasitism or the result of accidental brood mixing. Nonaccidental adoption has been suggested to be a post-hatch form of brood parasitism since many of the same benefits of parasitism through egg-laying could apply (Eadie et al., 1988), but this terminology has not been adopted universally. (c) Nest competition or takeover: two females (or mated pairs) compete for the same nest site, both lay eggs in the nest but eventually only one female (or pair) tends the nest (Semel \& Sherman, 2001; Wisenden, 1999) or in other cases one pair takes over an occupied nest and usurps the original owner (Robertson, 1998). (d) Nesting errors: females lay eggs in another's nests but the behaviour is not adaptive. This last scenario was long evoked for birds, but it is currently widely accepted that laying eggs in the nest of others is deliberate and adaptive in most cases (Lyon \& Eadie, 2008). (e) Egg stealing and offspring kidnapping: adults steal eggs or offspring (McKaye \& McKaye, 1977; Rohwer, 1978; Wisenden, 1999), behaviours that can have several benefits for the thief and that probably do not benefit the pilfered offspring. This discussion should make it clear that different biological mechanisms can lead to identical genetic signatures of mixed parentage broods and hence that genetic information alone cannot resolve the underlying behavioural mechanisms. Detailed behavioural observations are needed to fully distinguish among these five mechanisms, but such data are often difficult to obtain. Where such behavioural data are not possible, caution is required when interpreting genetic patterns.

With these theoretical expectations and potential caveats for genetic approaches in mind, we sampled broods of Altrichthys to determine if there was evidence for broods of mixed parentage, including mixed parentage within and across species. We then consider the possible mechanisms that could account for observed mixed parentage broods and conclude that both IBP and CBP occur in these two reef fishes. 


\section{Material \& Methods}

\subsection{Sampling}

We used clove oil solution and hand nets to sample broods while scuba diving, trying to collect all offspring in a brood (yet it is possible that occasionally a few individuals in a brood were not sampled). Care was taken to avoid sampling individuals from neighbouring broods, thus avoiding the possibility of sampling adjacent broods by mistake. A previous study showed that, on average, the distance between any Altrichthys nests was $3.9 \mathrm{~m}$, and the distance between nests of the same species was on average $5.1 \mathrm{~m}$ (Bernardi, Crane, et al., 2017; Bernardi, Longo, et al., 2017), with a minimum distance between nests of $0.8 \mathrm{~m}$. Sampled nests for this study were always at least $3 \mathrm{~m}$ from each other and no additional nests were within $3 \mathrm{~m}$ of the sampled nests. Predation levels are very high on coral reefs (Cortesi et al., 2015; Feeney et al., 2019), and the Calamian Archipelago is no exception. Anecdotal evidence showed us that when guarding parents were removed, offspring in a brood would be consumed by predators (mainly serranids, Cephalopholis microprion, and wrasses, Halichoeres leucurus, Oxycheilinus celebicus) in a matter of seconds (Bernardi, Crane, et al., 2017; Bernardi, Longo, et al., 2017). It is difficult to exclude the possibility that some offspring may hide deep in the coral to avoid predation, although this was not observed. For logistical reasons (avoiding damaging corals where adults hide), presumed parents (pair of adults associated with the brood) were not sampled. Because nests are deep within the coral substrate, we also did not sample eggs to avoid damaging the habitat. We collected 21 Altrichthys azurelineatus broods comprising 414 individuals and 19 A. curatus broods comprising 305 individuals from 10 localities in the Calamian Archipelago, Philippines (Figure 1, Table 1; Table S1). A previous study showed that some nests ( $7 \%$ of the observed nests) are composed of fry from different size classes (Bernardi, Crane, et al., 2017). For this study, we measured the size of sampled individuals to the nearest millimetre and ranked them in three size classes: $1(<7 \mathrm{~mm}), 2(7-13 \mathrm{~mm})$ and $3(>13 \mathrm{~mm})$. Within each cohort, there was very little variability in size between individuals (coefficient of variation was 0.546). 


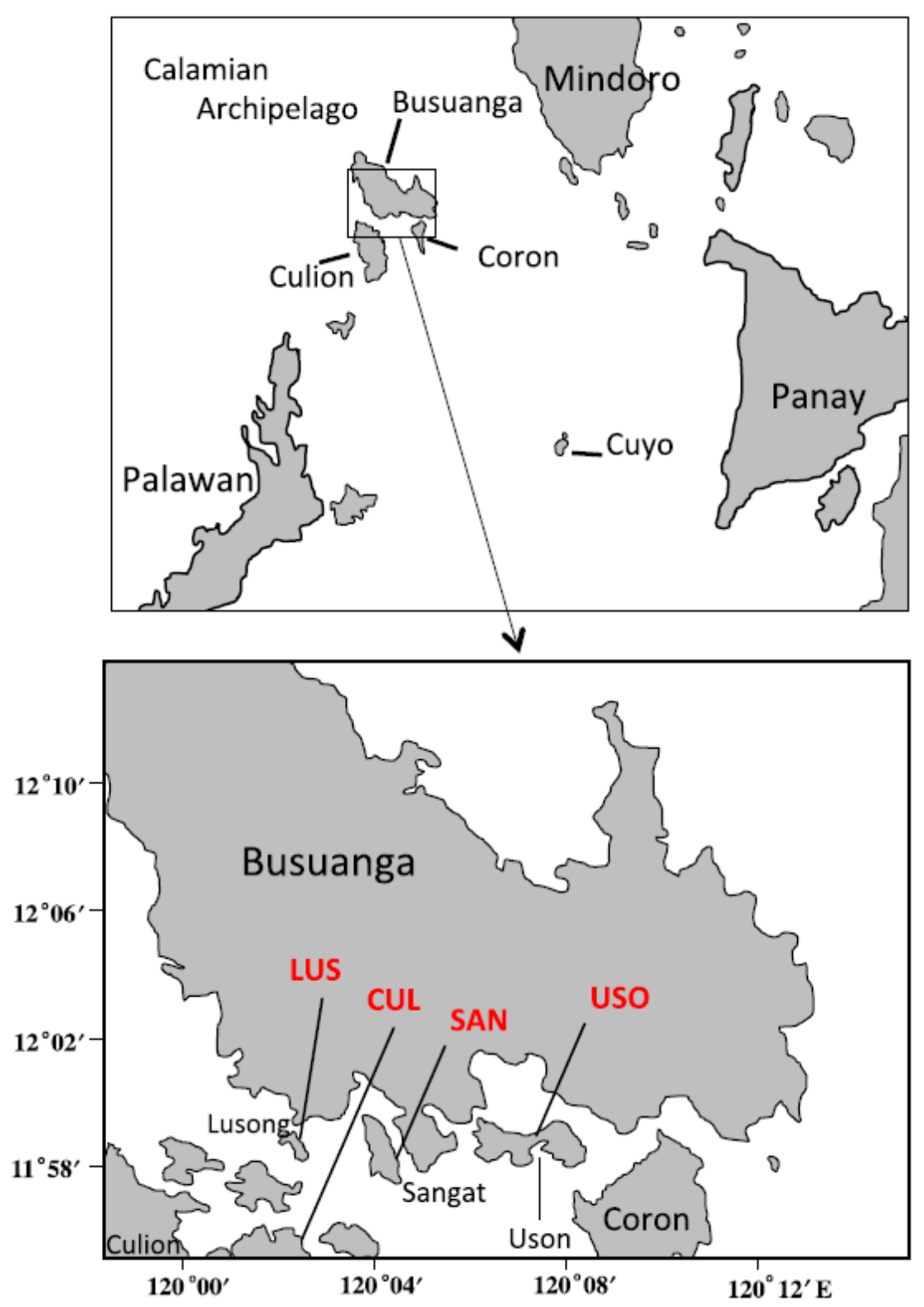

Figure 1. Sampling locations of Altrichthys broods (see also Table S1). Samples were collected on the islands of Uson (USO), Sangat (SAN) and Culion (CUL), in the Calamian Archipelago, Palawan, Philippines.

\subsection{Genotyping}

Since we collected very small offspring, we first used a genetic barcode to identify each individual at the species level. Four primers were used together to amplify a 655-bp fragment of the mitochondrial COI gene: FishF1, $5^{\prime}$-TCAACCAACCACAAAGACATTGGCA C-3'; FishF2, 5'-TCGACTAATCATAAAGATATCGGCAC-3'; FishR1, 5'-TAG ACTTCTGGGT GGCCAAAGAATCA-3'; and FishR2, 5'-ACTTCAGG GTGACCGAAGAATCAGAA-3' (Ward, Zemlak, Innes, Last, \& Hebert, 2005). Each polymerase chain reaction (PCR) of $25 \mu \mathrm{l}$ 
contained 10-100 ng DNA template $(0.5-2 \mu \mathrm{l}), 100 \mathrm{~nm}$ each of the four primers, $200 \mathrm{~mm}$ each dNTP, $2.5 \mathrm{~mm} \mathrm{MgCl}_{2}, 50 \mathrm{~mm} \mathrm{KCl}, 10 \mathrm{~mm}$ Tris- $\mathrm{HCl} \mathrm{pH} 8.3$ at $25^{\circ} \mathrm{C}$ and 1 unit of Taq polymerase. The reaction was amplified using the following programme: one cycle at $95^{\circ} \mathrm{C}$ for $2 \mathrm{~min} ; 35$ cycles at $94^{\circ} \mathrm{C}$ for $30 \mathrm{~s}, 54^{\circ} \mathrm{C}$ for $30 \mathrm{~s}$ and $72^{\circ} \mathrm{C}$ for $1 \mathrm{~min}$; one cycle at $72^{\circ} \mathrm{C}$ for $10 \mathrm{~min}$. The PCR products were visualized on $1 \%$ agarose gels. Each unexpected individual (from a different species than the majority of individuals within a brood) and a random selection of expected fish were sequenced with a combination of FishF1 and FishF2 primers. To positively identify the individual offspring, we also collected adults from several species of Amblyglyphidodon and Pomacentrus to match identifiable adults with sequences obtained from the offspring. Barcode sequences were also compared with BOLD (Barcode of Life) sequences to further confirm identification (Ratnasingham \& Hebert, 2007).

\subsection{Microsatellites}

To identify instances of conspecific brood parasitism, we genotyped each Altrichthys individual (previously identified by the barcoding approach described above) using microsatellites. Microsatellite primers originally described for the closely related Acanthochromis polyacanthus were used to genotype Altrichthys individuals (MillerSims, Delaney, Atema, Kingsford, \& Gerlach, 2005). Specifically, we used loci AC42, AC37, $\mathrm{AC}_{45}, \mathrm{POM}_{3}$ and POM15 following protocols described in the literature (Miller-Sims et al., 2005). PCRs were carried out with an ROX500 size standard. Peaks were called and binned with the microsatellite plugin of GENEIOUS version 8.1 (Kearse et al., 2012).

\subsection{Parentage analyses}

To assign relationships among individuals of a given brood, we used the software COLONY (Wang, 2004), a likelihood-based program that provides the most likely family configuration. Most default (zero option) parameters were used. We also used the following options: Mating system I-female polygamy, male polygamy (results remained unchanged when changing the setting to monogamy); Mating system II-with inbreeding, without clone; Species-dioecious, diploid; Length of run- medium; Analysis methodFull-likelihood; Likelihood precision-medium; Run specifications-Update allele frequency, no; Sibship scaling, yes, Number of runs, 2; Sibship prior-weak prior. These 


\begin{tabular}{|c|c|c|c|c|c|c|c|}
\hline Clutch & Locality & $\mathrm{n}$ & $\begin{array}{r}\text { Number of } \\
\text { families }\end{array}$ & $\begin{array}{r}\text { Number of } \\
\text { parasites }\end{array}$ & $\begin{array}{r}\text { Number of } \\
\text { extra sp }\end{array}$ & sp ID & $\begin{array}{l}\text { Offspring } \\
\text { size }\end{array}$ \\
\hline \multicolumn{8}{|c|}{ A. azurelineatus } \\
\hline 1 & USO1 & 16 & 6 & 5 & & & $00,00,16$ \\
\hline 2 & & 23 & 7 & 13 & 1 & $\mathrm{ACU}$ & $01,00,23$ \\
\hline 3 & & 24 & 3 & 3 & & & $00,00,24$ \\
\hline 4 & & 69 & 4 & 32 & & & $00,00,69$ \\
\hline 5 & USO2 & 16 & 3 & 8 & 8 & $\mathrm{ABA}$ & $16,05,03$ \\
\hline 6 & USO4 & 12 & 1 & 0 & $2+1$ & $\mathrm{PSM}+\mathrm{ABA}$ & $00,00,15$ \\
\hline 7 & & 47 & 2 & 1 & & & $47,00,00$ \\
\hline 8 & USO6 & 11 & 2 & 2 & & & $00,11,00$ \\
\hline 9 & & 32 & 3 & 2 & 5 & $\mathrm{ABA}$ & $00,37,00$ \\
\hline 10 & USO7 & 5 & 1 & 0 & & & $00,05,00$ \\
\hline 11 & & 6 & 1 & 0 & & & $00,00,06$ \\
\hline 12 & & 16 & 2 & 1 & 1 & $\mathrm{ABA}$ & $00,00,16$ \\
\hline 13 & & 31 & 3 & 13 & & & $00,31,00$ \\
\hline 14 & CUL1 & 6 & 2 & 1 & & & $00,06,00$ \\
\hline 15 & & 8 & 1 & 0 & & & $00,00,08$ \\
\hline 16 & & 15 & 3 & 2 & & & $00,00,15$ \\
\hline 17 & & 23 & 3 & 8 & & & $00,23,00$ \\
\hline 18 & LUS2 & 4 & 1 & 0 & & & $00,00,04$ \\
\hline 19 & SAN2 & 11 & 3 & 5 & & & $11,00,00$ \\
\hline 20 & & 30 & 2 & 6 & & & $30,00,00$ \\
\hline 21 & USO8 & 8 & 1 & 0 & 2 & $\mathrm{ABA}$ & N/A \\
\hline Total & & 414 & 2.6 & 4.8 & 20 & & \\
\hline Average & & 19.7 & & & 1.0 & & \\
\hline \multicolumn{8}{|c|}{ A. curatus } \\
\hline 1 & USO1 & 13 & 2 & 1 & & & $00,13,00$ \\
\hline 2 & & 18 & 1 & 0 & & & $18,00,00$ \\
\hline 3 & & 22 & 4 & 4 & & & $00,00,22$ \\
\hline 4 & USO4 & 3 & 2 & 1 & & & $00,02,03$ \\
\hline 5 & & 8 & 5 & 5 & & & $00,08,00$ \\
\hline 6 & & 10 & 1 & 0 & & & $00,00,10$ \\
\hline 7 & & 15 & 7 & 7 & & & $00,00,15$ \\
\hline 8 & CUL1 & 21 & 1 & 0 & & & $21,00,00$ \\
\hline 9 & & 23 & 2 & 11 & & & $00,00,23$ \\
\hline 10 & LUS1 & 16 & 1 & 0 & & & $00,16,00$ \\
\hline 11 & & 18 & 2 & 2 & & & $00,18,00$ \\
\hline 12 & USO8 & 7 & 3 & 2 & & & $00,00,07$ \\
\hline 13 & & 8 & 2 & 4 & & & $00,00,08$ \\
\hline 14 & & 12 & 3 & 4 & & & $00,12,00$ \\
\hline 15 & & 19 & 2 & 1 & & & $00,19,00$ \\
\hline 16 & & 20 & 2 & 6 & & & $20,00,00$ \\
\hline 17 & & 21 & 3 & 2 & & & $00,00,21$ \\
\hline 18 & & 25 & 6 & 6 & & & $00,25,00$ \\
\hline 19 & & 26 & 3 & 5 & 4 & AAZ & $04,26,00$ \\
\hline Total & & 305 & 52 & 61 & & & \\
\hline Average & & 16.1 & 2.7 & 3.2 & & & \\
\hline
\end{tabular}

Table 1. Altrichthys brood parasite counts. Columns correspond to: clutch identification number, sampling locality (see Figure 1 for abbreviation), number of individuals in the clutch, number of identified families in the clutch, number of parasitic individuals, number of extraspecific individuals, and their identity. Extraspecific individuals were: AAZ, Altrichthys azurelineatus; ABA, Amblygliphidodon batunai; ACU, Altrichthys curatus; PSM, Pomacentrus smithi. Sizes of offspring, when available, are shown in three classes, given as 1 ( $<7 \mathrm{~mm}), 2(7-13 \mathrm{~mm})$ and $3(>13 \mathrm{~mm})$. Numbers of offspring belonging to each size class 1, 2 and 3 are given in that order. 
parameters are commonly used in the literature because they generally provide robust results (Reisser, Beldade, \& Bernardi, 2009). colony identified families of full sibs (no halfsibships were detected). For this study, we assumed that the largest group of siblings in each nest was the host brood, and all other offspring not included in that group of siblings were considered parasitic.

\section{Results}

\subsection{Species identifications/barcoding}

Based on COI barcodes, we genotyped a total of 719 individuals belonging to 40 different broods (21 Altichthys azurelineatus, and 19 A. curatus broods). All individuals were identified as damselfishes including 398 A. azurelineatus, 300 A. curatus, 19 Amblyglyphidodon batunai and two Pomacentrus smithi (Table 1).

\subsection{Interspecific mixed parentage broods}

Interspecific parentage was found in eight of 40 broods (20\%), but only corresponded to 26 of 719 individuals (3.5\%) (Table S1). There was no statistical difference in the frequency of these mixed broods between A. azurelineatus and A. curatus broods (six of 21 broods were mixed in A. azurelineatus, two of 19 broods were mixed in A. curatus, $\chi^{2}$ test, $\mathrm{p}=$ .15). We did not find a correlation between the size of the brood and the presence of interspecific offspring ( $\mathrm{df}=1, \mathrm{~F}$-ratio $=1.35, \mathrm{p}=.29$ ). All of the foreign offspring were damselfishes and the majority of them were Amblyglyphidodon batunai (19 of 26). Adult Amblyglyphidodon batunai are common in the area where broods were sampled, but their density was not estimated. Two foreign offspring were identified as Pomacentrus smithi, and adults of that species are also very common. Finally, one A. curatus was present in an A. azurelineatus brood and four A. azurelineatus were found in an A. curatus brood (Table 1).

\subsection{Conspecific mixed parentage broods}

Conspecific mixed broods were found in 30 out of 40 broods (75\%), corresponding to 163 out of 719 individuals (22.7\%) (Table 1, Figure 2). There was no statistical difference in the frequency of mixed broods between $A$. azurelineatus and $A$. curatus broods (15 of 21 broods were mixed in A. azurelineatus, 15 of 19 broods were mixed in A. curatus, $\chi^{2}$ test, $\mathrm{p}=.58$ ). Unlike the situation with interspecific mixed broods, brood size was correlated 

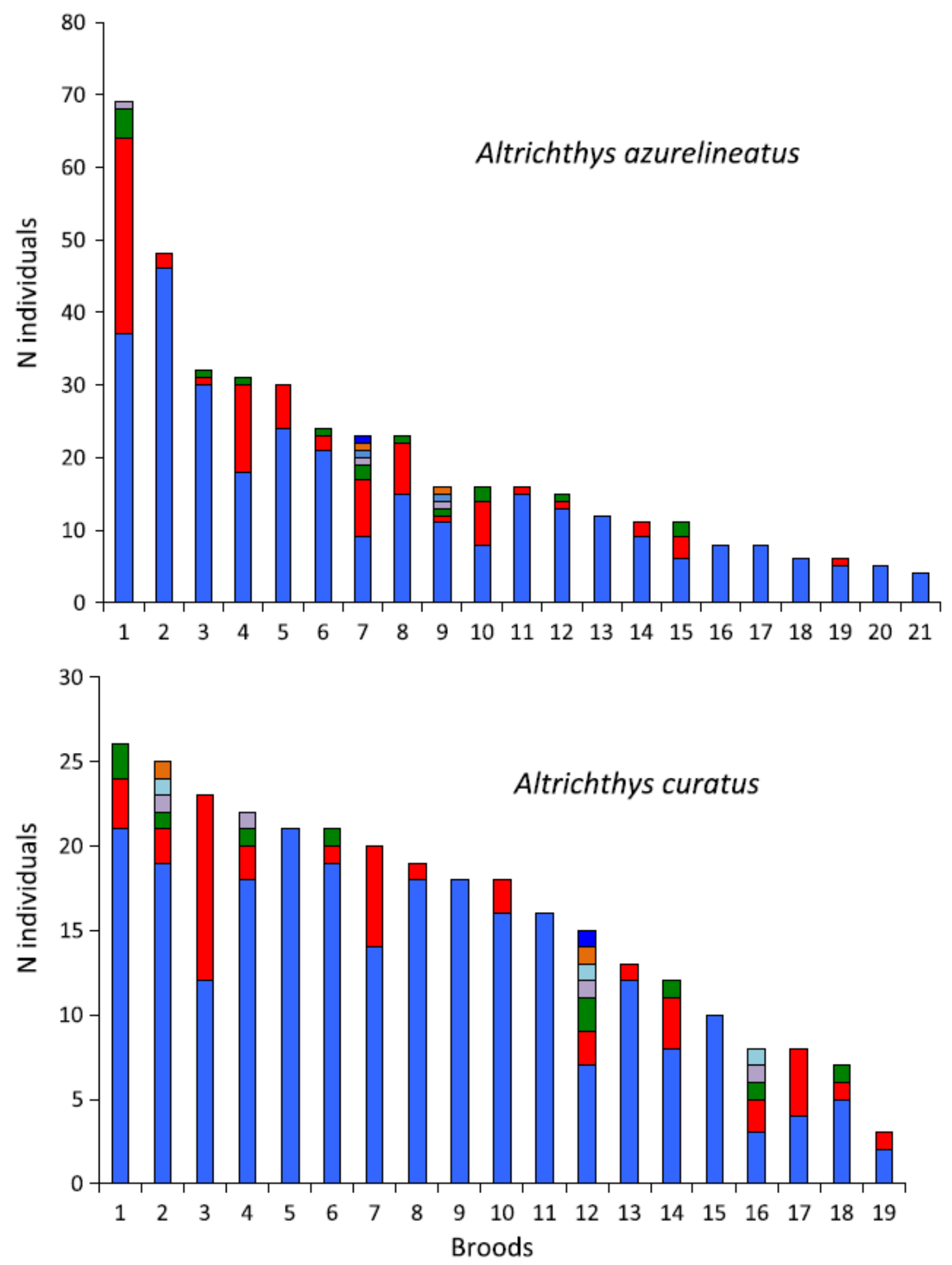

Figure 2. Composition of Altrichthys broods. Each bar represents a single brood (21 broods for $A$. azurelineatus, 19 broods for $A$. curatus). Numbers of individuals per brood are indicated on the y-axis. Colours represent families within each brood. For example, brood 5 in $A$. curatus corresponds to a single family (no parasites) with 21 individuals (a single colour), while brood 5 in A. azurelineatus includes two families (two colours) with a total of 30 individuals. 
with the presence of foreign conspecific offspring $(\mathrm{df}=1, \mathrm{~F}-$ ratio $=38.69, \mathrm{p}<.001)$. A large number of singletons (a single foreign individual from given alloparents) were found (41 individuals). On the other hand, mixed broods containing groups of siblings from the same alloparents, from two to 27 individuals, accounted for the remaining 124 foreign offspring. We did not find any half-sibs in our data set, meaning that there was no evidence of conspecific spawn sneaking behaviour. All raw data that support the findings of this study are provided in the Supporting Information.

\subsection{Size ranges}

We measured the sizes of individuals in broods and placed them in three size classes (Table 1). For A. azurelineatus, out of 20 broods, four were in class 1 , six in class 2 and 10 in class 3. For A. curatus, out of 19 broods, three, eight, and eight were in size classes 1, 2 and 3 , respectively. Broods containing different size classes of offspring were found in two out of five interspecific mixed broods and two out of two IBP broods for A. azurelineatus and $A$. curatus, respectively. In contrast, none of the other broods, including those affected by conspecific brood parasitism, contained more than one size class (Table 1). In addition, we did not find evidence of a relationship between size of the brood and incidence of mixed parentage broods.

\section{Discussion}

Neither adoption nor brood parasitism has been previously described in coral reef fishes. Due to the peculiarities of coral reef fish life history (lack of parental care), very few species are susceptible to brood parasitism in the first place, yet, as we suggest, brood parasitism is indeed present in apelagic species. Here we show evidence of patterns that are consistent with both interspecific adoption and conspecific brood adoption and parasitism in Altrichthys.

\subsection{Evidence for interspecific brood adoption}

The frequency of interspecific mixed brood was low; it involved only $3.5 \%$ of individuals and in all cases the foreign offspring were damselfishes. However, we must distinguish two types of potential interspecific alloparental care that are very different. The most common type of mixed broods involved non-Altrichthys damselfishes, namely Amblyglyphidodon batunai and Pomacentrus smithi. These two species guard demersal 
eggs (a trait shared by all damselfishes), which turn into pelagic larvae after hatching. Larvae remain in the water column for 12-20 days in Amblyglyphidodon and 14-23 days in Pomacentrus (Wellington \& Victor, 1989). Therefore, at recruitment time, larvae join Altrichthys broods, probably to gain protection provided by Altrichthys parents. We propose that these mixed broods are cases of adoption after hatching. We did not specifically quantify the aggressive behaviour of the parents, but when we could distinguish Altrichthys offspring from other species, we could see directed aggression towards the foreign offspring. While Altrichthys parents tend to be aggressive towards any potential threat to the brood, non-Altrichthys larvae generally benefit from this protection, even if sometimes being themselves targeted. Other species of damselfishes are very common on the studied reefs, in particular the very abundant Chrysiptera springeri and Pomacentrus stigma (the latter very closely resembles Altrichthys), although neither was found to have their offspring adopted by Altrichthys.

The relatively small number of these interspecific foreign offspring in host broods might suggest this form of alloparental care is so rare as to be unimportant to the adopted offspring, but our observations suggest otherwise. We did not follow the fate of specific broods over time, but we witnessed a massive recruitment event of Pomacentrus smithi that resulted in very large numbers of new settlers on the reef. In the course of few days, most settlers disappeared, presumably due to natural predation, which is consistent with the massive mortality incurred by coral reef fishes with a pelagic larval stage (Almany \& Webster, 2006; Goatley \& Bellwood, 2016). The remaining few visible ones were invariably seen in association with Altrichthys broods (two of them being identified in this genetic study), supporting the idea that an association with Altrichthys broods may increase survivorship for parasitic damselfishes. Moreover, although the total number of adoptees was small in terms of the fraction of total offspring in host broods, the fact that the only Pomacentrus recruits were seen in association with host broods indicates that adoption might be important for Pomacentrus smithi in the region of overlap with Altrichthys. Interspecific brood associations can range from parasitic, commensal to mutualistic relationships (Canestrari et al., 2014; Johnston, 1994; McKaye, 1985). The fact that the Altrichthys hosts in our study were often aggressive to the adopted offspring suggests that these adoptees might be costly to the hosts, and hence a form of reproductive 
parasitism by the foreign offspring, but experimentally assessing the costs to hosts would be required to understand the nature of the relationship.

Our observations suggest that predation may be the key factor driving interspecific adoption in Amblyglyphidodon batunai and Pomacentrus smithi. Predation is known to be a potent factor favouring interspecific interactions in fish generally (Hay et al., 2004) and evidence suggests that the benefits of protective associations may be strongest for smaller, younger age classes because these are particularly vulnerable to predation (Feeney et al., 2019). Predation is similarly thought to be the main factor in most of the previously studied cases of interspecific mixed clutches and broods in fish, most of which occur in freshwater systems (Baba et al., 1989; Goff, 1984; Johnston, 1994; McKaye, 1985). However, predation was also thought to be a key factor in the one previous example of mixed interspecific clutches in a marine fish (Kent et al., 2011).

Protection from predation has also been suggested as an important factor in some forms of avian brood parasitism, mostly notably in the adoption that occurs in waterfowl species with precocial young that do not require food from the parents and for which protection from predators seems particularly important (Canestrari et al., 2014; Eadie et al., 1988; Eadie \& Lyon, 1998). In these species, broods with mixed young can occur either by females laying eggs in the nests of other females or by adoption of offspring after hatching, which is sometimes facilitated by mothers that desert their offspring near females who will then adopt the offspring (Eadie et al., 1988). There has been debate over whether this adoption is parasitic because host females could benefit through dilution of predation risk to their own offspring (Andersson, 1984; Eadie et al., 1988) In an experimental study of adoption in waterfowl, host females were very aggressive to ducklings that differed in size from their own offspring, sometimes even infanticidal, suggesting that adoption might not benefit the host (Eadie \& Lyon, 1998).

The other type of interspecific mixed brood was even less common and involved Altrichthys individuals. We only found one A. curatus individual in an A. azurelineatus brood and four $A$. azurelineatus in an A. curatus brood. The presence of the single $A$. curatus parasitic individual may correspond to an individual swimming from one brood to another interspecific brood. The paucity of these observations, however, may indicate a strong cue and aggressivity towards congeneric offspring. Alternatively, the observed 
rarity of adoption between Altrichthys species would be expected if conspecific parental care is superior to heterospecific care-if so, offspring should strongly prefer parasitizing their own species as hosts. The issue then is not lack of foreign offspring in Altrichthys generally, but the relative distribution of interspecific vs. conspecific adoptions. Adoption and parasitism is common but it mostly occurs as CBP rather than IBP.

\subsection{Conspecific brood adoption and parasitism (CBP)}

Conspecific adoption and brood parasitism was found to be rampant in Altrichthys, comprising over $20 \%$ of individuals. However, as with interspecific mixed broods, two patterns emerged that probably represent different forms of parasitism or adoption. In 41 broods, a single foreign individual was involved in the parasitism. In other broods, the parasitism involved groups of individuals, invariably siblings. A simple interpretation of this pattern is that, similarly to the interspecific examples described above, broods that involve single (or few) foreign individuals arise after hatching by the offspring swimming from one nest to another. In fact, we have occasionally observed groups of a few individuals swimming together and being chased by some parents protecting their own brood. This is easy to identify in the field when the intruders have distinctly different sizes than the brood. It is less clear for us (and potentially for the parents) to identify intruders when their size is similar to the parents' own brood.

An alternative situation occurs when a large group of individuals is involved in the parasitic event, for example A. azurelineatus brood 1, and A. curatus brood 3 (Figure 2). In those cases, broods are mainly composed of two genetic families of offspring that have similar sizes (brood 1:37, 27 individuals; brood 3:12, 11 individuals). Given the very high predation pressure on juvenile fishes, while very unlikely, it is not possible to entirely exclude that a group of offspring moved to another brood after hatching. However, a more plausible explanation is that a second pair of adults spawned in the nest and would have thus directly parasitized the parents. This is because the mortality of offspring swimming away from shelters and parental protection is likely to be extremely high; with such mortality, the possibility that large numbers of siblings successfully swim to a new nest site is remote. Importantly, regardless of the mechanism, mixed parentage broods are frequent and probably arise from both adoption of offspring and brood parasitism by parents. The large frequency of conspecific mixed broods is also consistent with the 
observation that there is a significant relationship between mixed broods and brood size, since adoption and parasitism directly contribute to brood size. In avian studies, this same relationship between clutch size and parasitism has been observed and has been used as a method for detecting brood parasitism (Eadie, Smith, Zadworny, Kühnlein, \& Cheng, 2010).

As with many genetic studies of parasitism, we have been able to detect the occurrence of brood parasitism (mixed clutches) and post-hatching adoption, but we currently lack the ecological and demographic information required to understand why this behaviour occurs and how the parasites benefit (Andersson, 1984; Lyon \& Eadie, 2008; Wisenden, 1999). Parental care improves the survival of the offspring but it can also result in costs to parents (Trivers, 1972). In Acanthochromis, there is a direct cost of producing mucus to feed and potentially transfer microbiomes to the offspring, as well as a chance of the adult being preyed upon while aggressively defending the brood (Jordan et al., 2013). In an experimental setting at the Great Barrier Reef (Jordan et al., 2013), broods were manipulated to estimate parental cost and aggression towards potential intruders. After removing Acanthochromis offspring from a brood, mixed brood (host and parasites) as well as original broods were returned to the parents. The parents then showed more aggression towards parasites than their own brood, chasing the parasites far enough from the nest to be vulnerable to predation. In the Calamian Archipelago, we observed almost instant predation on offspring by several fish species (e.g. Cephalopholis microprion, Halichoeres leucurus and Oxycheilinus celebicus) when parents were removed (Bernardi, Crane, et al., 2017; Bernardi, Longo, et al., 2017). While we did not observe mucous feeding in offspring, we did observe parents chasing individuals from the brood away from the nests; these "offspring" could potentially represent parasites. Apparently, this chasing behaviour is not fully efficient, since a relatively large proportion of the broods were found with adopted offspring.

When CBP is frequent, as for Altrichthys, the amount of parasitism should not be so great as to jeopardize the integrity of the system. Another possibility is that the entire population size of either species of Altrichthys is relatively small (the entire range of the species is restricted to the Calamian Archipelago; Bernardi, Crane, et al., 2017). This may mean that individuals are related, thus allowing for some altruism to be present due to 
genetic relatedness. Kin-selected aspects of brood parasitism have been suggested for some avian conspecific parasites as well (Andersson, 1984; Lyon \& Eadie, 2008). As mentioned above, in general, free larvae cannot swim long distances over reefs without incurring high levels of mortality. The distance between nests that we observed, $\sim 5 \mathrm{~m}$, may be structured by the dynamics of parasitism.

\section{Conclusions}

Our results are consistent with interspecific adoption and both CBP and adoption in two species of Altrichthys. A previous study on Acanthochromis polyacanthus suggests that CBP is probably present in that species as well. Indeed, on the Great Barrier Reef, a study aimed at estimating dispersal of Acanthochromis polyacanthus between reefs used an ecological approach by genotyping broods (Miller-Sims, Gerlach, Kingsford, \& Atema, 2008). That study found that broods (groups of siblings) remain together from birth to being fully independent and beyond. In that study, 30 broods were genotyped, and one incongruent brood was discarded from the analysis. That discarded brood was the largest one, with 43 individuals, and included over $50 \%$ of individuals originating from different parents (Miller-Sims et al., 2008). We think that this brood presents strong evidence for mixed broods in Acanthochromis. If this were the case, broods of mixed parentage would be present in all three tested species of apelagic fishes, Acanthochromis polyacanthus, Altrichthys azurelineatus and Altrichthys curatus.

Our study adds to the list of taxonomic groups that show some form of brood parasitism or adoption and, as such, increases our ability to understand which aspects of brood parasitism and adoption are general, and which are specific to particular sets of taxa. In fishes, interspecific mixed parentage broods appear to be much more common that conspecific mixed broods. It is unclear whether this pattern reflects the actual distribution of parasitism types because interspecific cases are considerably easier to detect because they are often apparent based on morphological differences between hosts and parasites whereas genetic methods or very careful demographic studies are required to detect conspecific cases. This same pattern and problem was observed for brood parasitism in birds-three decades ago the occurrence of IBP was accurately known (100 species) and was thought to be the dominant form of parasitism because few examples of CPB were known (Andersson, 1984; Lyon \& Eadie, 2008). The advent of modern genetic parentage 
methods over the intervening years has revealed that CBP is actually more common than previously imagined, having now been documented in some 230 species (Lyon \& Eadie, 2008). Studies are now needed to determine whether this same trajectory will also apply to fish, or whether the CBP we have discovered is unusual.

Brood parasitism and adoption allows individuals to gain the benefits of parental care without paying the cost of care, but the nature of the relationship between host and donor should depend of the type of parental care. Some forms of care, like food for offspring, are "depreciable" (Altmann, Wagner, \& Lenington, 1977) in that the same unit of care cannot be spread among several offspring. Given this, family size is likely to be limited by the parental care and, accordingly, raising the offspring of others can impose high fitness costs to the hosts by reducing the number of host offspring produced. Other forms of parental care, such as protecting offspring from predators, are much more likely to be able to be shared among offspring; parasitism of this form of parental care may be less costly to hosts and, in some cases, could even benefit hosts where there is safety in offspring numbers (Andersson, 1984; Johnston, 1994). In birds, the type of brood parasitism is closely linked to the form of parental care-all but one of the 100 species of obligate interspecific brood parasites have altricial offspring that require large amounts of food (Davies, 2000; Lyon \& Eadie, 1991). In these species, costs to hosts are often high and these costs have fuelled coevolutionary arms races between defensive traits in the hosts and traits in the parasites to thwart the host defences (Davies, 2000; Feeney, Welbergen, \& Langmore, 2014; Rothstein, 1990). Although some forms of avian intraspecific brood parasitism also parasitize depreciable forms of care like food, intraspecific brood parasitism is particularly widespread in species with precocial offspring that feed themselves and for which protection from predation is a key aspect of parental care (Andersson, 1984; Davies, 2000; Lyon \& Eadie, 2008). The forms of interspecific brood associations widely reported in fishes (Johnston, 1994; McKaye \& McKaye, 1977; Wisenden, 1999), and that we show here for both interspecific and intraspecific mixed broods in coral reef fish, probably share more in common with the brood parasitism seen in precocial birds.

\section{Acknowledgements}

We thank Amalia Bernardi and Alessio Bernardi for help in the field. We thank the following: Bureau of Fisheries and Aquatic Resources (Commodity Clearance 2016- 
20091), Palawan Council for Sustainable Development (PCSD, GP 2016-03, Wildlife Transport Permit No. 2016-05-000062-DMO-Calamianes, Fisheries inspection and quarantine clearance Permit no. 009391) and Leonora Labrador and Eva Palanca of the Coron PCSD office. Ateneo de Manila University's Hendrik Freitag, Merab A. Chan, Jonathan Patrick H. Yan are thanked for the Memorandum of Agreement between UCSC and the Department of Biology at Ateneo de Manila. Busuanga Mayor (Samuel de Jesus) and Councilor (Ann D. Mercado), Coron Mayor (Clara Espiritu-Reyes) and Samuel Madamba, Culion Mayor (Emiliano Marasigan) and Councilor Leonilo Sarmiento are thanked for Prior Informed Consent (PIC), given in 2015. Hikari South Sea Pearl, Luna Sombrano, Agustin R. Badon II, Eric T. Dalisay and Pinky Perpetua helped in obtaining the PICs. We thank Dive Link Resort, Balinsasayaw Island, El Rio y Mar Resort and Dirk Fahrenbach at the Dugong Dive Center for letting us visit their reefs, and Gerald Allen and Kathryn Kavanagh for discussing our data and invaluable information on Altrichthys. We thank editor C. Riginos, W. Feeney and two anonymous reviewers for feedback that greatly improved the paper. This work was funded by a National Geographic Grant 9399-13, and a UCSC Committee on Research (COR) grant to G.B.

\section{Data accessibility statement}

All data that support the findings of this study are available as an electronic Supporting Information on the Wiley's website.

\section{ORCID}

Bruce E. Lyon https://orcid.org/0000-0001-8733-9944

Giacomo Bernardi https://orcid.org/0000-0002-8249-4678

\section{Références}

Allen, G. R. (1999). Altrichthys, a new genus of damselfish (Pomacentridae) from Philippine seas with description of a new species. Revues Francaise d' Aquariologie, 26, 23-28.

Almany, G. R., \& Webster, M. S. (2006). The predation gauntlet: Early post-settlement mortality in reef fishes. Coral Reefs, 25(1), 19-22. https://doi.org/10.1007/s00338-005-0044-y

Altmann, S. A., Wagner, S. S., \& Lenington, S. (1977). Two models for the evolution of polygyny. Behavioral Ecology and Sociobiology, 2(4), 397-410. https://doi.org/10.1007/BFo02 99508 
Andersson, M. (1984). Brood parasitism within species. In C. Barnard (Ed.), Producers and scroungers: Strategies of exploitation and parasitism (pp. 195-228). London, UK: Croom Helm.

Avise, J. C., Jones, A. G., Walker, D., \& DeWoody, J. A. (2002). Genetic mating systems and reproductive natural histories of fishes: Lessons for ecology and evolution. Annual Review of Genetics, 36, 19-45. https://doi.org/10.1146/annur ev.genet.36.030602.090831

Baba, R., Nagata, Y., \& Yamagishi, S. (1989). Brood parasitism and egg robbing among three freshwater fish. Animal Behaviour, 40, 776-778. https://doi.org/10.1016/So003-3472(05)80707-9

Barlow, G. W. (1981). Patterns of parental investment, dispersal and size among coralreef fishes. Environmental Biology of Fishes, 6(1), 65-85. https://doi.org/10.1007/BF000 01801

Bernardi, G. (2011). Monophyletic origin of brood care in damselfishes. Molecular Phylogenetics and Evolution, 59(1), 245-248. https://doi.org/10.1016/j.ympev.2010.12.021

Bernardi, G., Crane, N. L., Longo, G. C., \& Quiros, A. L. (2017). The ecology of Altrichthys azurelineatus and $A$. curatus, two damselfishes that lack a pelagic larval phase. Environmental Biology of Fishes, 100, 111- 120. https://doi.org/10.1007/s10641-016-0559-9

Bernardi, G., Longo, G. C., \& Quiros, T. E. A. L. (2017). Altrichthys alelia, a new brooding damselfish (Teleostei, Perciformes, Pomacentridae) from Busuanga Island, Philippines Giacomo. ZooKeys, 675, 45-55. https://doi.org/10.3897/zooke ys.675.12061

Blažek, R., Polačik, M., Smith, C., Honza, M., Meyer, A., \& Reichard, M. (2018). Success of cuckoo catfish brood parasitism reflects coevolutionary history and individual experience of their cichlid hosts. Science Advances, 4(May), eaar4380. Retrieved from http://advances.sciencemag.org/content/advances/4/5/eaar4380.full.pdf

Boulton, A., \& Polis, G. A. (2002). Brood parasitism among spiders: Interactions between Salticids and Diguetia mojavea. Ecology, 83(1), 282-287. https://doi.org/10.2307/2680138

Brown, J. L., Twomey, E., Morales, V., \& Summers, K. (2008). Phytotelm size in relation to parental care and mating strategies in two species of Peruvian poison frogs. Behaviour, 145, 1139-1165. https://doi.org/10.1163/156853908785387647

Buschinger, A. (1986). Evolution of social parasitism in ants. Trends in Ecology and Evolution, 1(6), 155-160. https://doi.org/10.1016/0169-5347(86)90044-3

Buschinger, A. (2009). Social parasitism among ants: A review (Hymenoptera: Formicidae). Myrmecological News, 12, 219-235.

Canestrari, D., Bolopo, D., Turlings, T. C. J., Röder, G., Marcos, J. M., \& Baglione, V. (2014). From parasitism to mutualism: Unexpected interactions between a cuckoo and Its host. Science, 343(March), 1350-1352.

Clutton-Brock, T. H. (1991). The evolution of parental care. Princeton, NJ: Princeton University Press.

Cortesi, F., Feeney, W. E., Ferrari, M. C. O., Waldie, P. A., Phillips, G. A. C., McClure, E. C., ... Cheney, K. L. (2015). Phenotypic plasticity confers multiple fitness benefits 
to a mimic. Current Biology, 25, 949-954.

https://doi.org/10.1016/j.cub.2015.02.013

Davies, N. B. (2000). Cuckoos, cowbirds and other cheats. London, UK: T \& A.D. Poyser.

Dierkes, P., Taborsky, M., \& Kohler, U. (1999). Reproductive parasitism of broodcare helpers in a cooperatively breeding fish. Behavioral Ecology, 10(5), 510-515. https://doi.org/10.1093/behec 0/10.5.510

Eadie, J. M., Kehoe, F. P., \& Nudds, T. D. (1988). Pre-hatch and post-hatch brood amalgamation in North American Anatidae: A review of hypotheses. Canadian Journal of Zoology, 66(8), 1709-1721. https://doi.org/10.1139/z88-247

Eadie, J. M., \& Lyon, B. E. (1998). Cooperation, conflict, and crèching behavior in goldeneye ducks. The American Naturalist, 151, 397-408.

https://doi.org/10.1086/286128

Eadie, J. M., Smith, J. N. M., Zadworny, D., Kühnlein, U., \& Cheng, K. (2010). Probing parentage in parasitic birds : An evaluation of methods to detect conspecific brood parasitism using goldeneyes Bucephala islandica and Bl. clangula as a test case. Journal of Avian Biology, 41(May), 163-176. https://doi.org/10.1111/j.16oo048X.2009.04735.x

Fautin, D. G., \& Allen, G. R. (1997). Anemonefishes and their Host Sea Anemones. Perth, WA, Australia: Western Australian Museum.

Feeney, W. E., Brooker, R. M., Johnston, L. N., Gilbert, J. D. J., Besson, M., Lecchini, D., ... Manica, A. (2019). Predation drives recurrent convergence of an interspecies mutualism. Ecology Letters, 22, 256-264. https://doi.org/10.1111/ele.13184

Feeney, W. E., Welbergen, J. A., \& Langmore, N. E. (2014). Advances in the study of coevolution between avian brood parasites and their hosts. Annual Review of Ecology Evolution and Systematics, 45, 227- 248. https://doi.org/10.1146/annur ev-ecolsys-120213-091603

Goatley, H. R. C., \& Bellwood, D. R. (2016). Body size and mortality rates in coral reef fishes: A three-phase relationship. Proceedings of the Royal Society B, 283, 20161858.

Goff, G. P. (1984). Brood care of longnose gar (Lepisosteus osseus) by smallmouth bass (Micropterus dolomieui). Copeia, 1984(1), 149-152.

https://doi.org/10.2307/1445046

Gross, M. R. (2005). The evolution of parental care. Quarterly Review of Biology, 80(1), 37-45. https://doi.org/10.1086/431023

Hay, M. E., Parker, J. D., Burkepile, D. E., Caudill, C. C., Wilson, A. E., Hallinan, Z. P., \& Chequer, A. D. (2004). Mutualism and aquatic community structure: The enemy of my enemy Is my friend. Annual Review of Ecology and Systematics, 35, 175197. https://doi.org/10.1146/annurev.ecolsys.34.011802.132357

Holldobler, B., \& Wilson, E. O. (1990). The ants. Berlin, Germany: Springer.

Johnston, C. E. (1994). The benefit to some minnows of spawning in the nests of other species. Enviromental Biology of Fishes, 40, 213-218.

https://doi.org/10.1007/BFo0002547

Jordan, L. A., Herbert-Read, J. E., \& Ward, A. J. W. (2013). Rising costs of care make spiny chromis discerning parents. Behavioral Ecology and Sociobiology, 67(3), 449-455. https://doi.org/10.1007/s00265-012-1465-6 
Kavanagh, K. (1998). Notes on the frequency and function of glancing behavior in juvenile Acanthochromis (Pomacentridae). Copeia, 1998(2), 493-496.

https://doi.org/10.2307/1447449

Kavanagh, K. D. (2000). Larval brooding in the marine damselfish Acanthochromis polyacanthus (Pomacentridae) is correlated with highly divergent morphology, ontogeny and life-history traits. Bulletin of Marine Science, 66(2), 321-337.

Kearse, M., Moir, R., Wilson, A., Stones-Havas, S., Cheung, M., Sturrock, S., ... Drummond, A. (2012). geneious basic: An integrated and extendable desktop software platform for the organization and analysis of sequence data.

Bioinformatics, 28(12), 1647-1649. https://doi.org/10.1093/bioinforma $\underline{\text { tics} / \text { bts199 }}$

Kent, D. I., Fisher, J. D., \& Marliave, J. B. (2011). Interspecific nesting in marine fishes: Spawning of the spinynose sculpin, Asemichthys taylori, on the eggs of the buffalo sculpin, Enophrys bison. Ichthyological Research, 58(4), 355-359. https://doi.org/10.1007/s10228-011-0223-5

Kruger, O., \& Pauli, M. (2018). Evolution of avian brood parasitism and phylogenetic history of brood parasites. In M. Soler (Ed.), Avian brood parasitism. Cham, the Netherlands: Springer.

Leis, J. (1991). The pelagic stage of reef fishes. In P. Sales (Ed.), The ecology of fishes on coral reefs (pp. 182-229). San Diego, CA: Academic Press Inc.

Lyon, B. E., \& Eadie, J. M. (1991). Mode of development and interspecific avian brood parasitism. Behavioral Ecology, 2(June), 309-318.

https://doi.org/10.1093/beheco/2.4.309

Lyon, B. E., \& Eadie, J. M. (2004). An obligate brood parasite trapped in the intraspecific arms race of its hosts. Nature, 432(7015), 390-393. https://doi.org/10.1038/nature03036

Lyon, B. E., \& Eadie, J. M. (2008). Conspecific brood parasitism in birds: A life-history perspective. Annual Review of Ecology, Evolution, and Systematics, 39(1), 343363. https://doi.org/10.1146/annurev.ecolsys.39.110707.173354

McKaye, K. R. (1985). Cichlid-catfish mutualistic defense of young in Lake Malawi, Africa. Oecologia, 66, 358-363. https://doi.org/10.1007/BFo0378298

McKaye, K. R., \& McKaye, N. M. (1977). Communal care and kidnapping of young by parental cichlids. Evolution, 31(3), 674-681. https://doi.org/10.1111/j.15585646.1977.tb010 59.x

Miller-Sims, V., Delaney, M., Atema, J., Kingsford, M., \& Gerlach, G. (2005). DNA microsatellites in Acanthochromis polyacanthus. Molecular Ecology Notes, 5(4), 841-843. https://doi.org/10.1111/j.1471-8286.2005.01081.x

Miller-Sims, V. C., Gerlach, G., Kingsford, M. J., \& Atema, J. (2008). Dispersal in the spiny damselfish, Acanthochromis polyacanthus, a coral reef fish species without a larval pelagic stage. Molecular Ecology, 17(23), 5036-5048.

https://doi.org/10.1111/j.1365-294X.2008.03986.x

Mrowka, W. (1987a). Brood adoption in a mouthbrooding cichlid fish: Experiments and a hypothesis. Animal Behaviour, 35(3), 922-923.

https://doi.org/10.1016/Soo03-3472(87)80128-8 
Mrowka, W. (1987b). Egg stealing in a mouthbrooding cichlid fish. Animal Behaviour, 35(3), 923-925. https://doi.org/10.1016/ Soo03-3472(87)80129-X

Noakes, D. L. G. (1979). Parent-touching behavior by young fishes: Incidence, function and causation. Environmental Biology of Fishes, 4(4), 389-400.

https://doi.org/10.1007/BFo0005529

Ratnasingham, S., \& Hebert, P. D. N. (2007). BOLD: The barcode of life data system (http://www.barco dingl ife.org). Molecular Ecology Notes, 7(3), 355-364. https://doi.org/10.1111/j.1471-8286.2006.01678.x

Reisser, C. M. O., Beldade, R., \& Bernardi, G. (2009). Multiple paternity and competition in sympatric congeneric reef fishes, Embiotoca jacksoni and E. lateralis. Molecular Ecology, 18(7), 1504-1510. https://doi.org/10.1111/j.1365294X.2009.04123.X

Robertson, D. R. (1973). Field observations on the reproductive behaviour of a pomacentrid fish, Acanthochromis polyacanthus. Zeitschrift für Tierpsychologie, 32, 319-324. https://doi.org/10.1111/j.1439-0310.1973.tbo1108.x

Robertson, G. J. (1998). Egg adoption can explain joint egg-laying in common eiders. Behavioral Ecology and Sociobiology, 43, 289-296. https://doi.org/10.1007/s002650050493

Rohwer, S. (1978). Parent cannibalism of offspring and egg raiding as a courtship strategy. The American Naturalist, 112(984), 429-440. https://doi.org/10.1086/283284

Rothstein, S. I. (1990). A model system for coevolution: Avian brood parasitism. Annual Review of Ecology and Systematics, 21, 481-508. https://doi.org/10.1146/annurev.es.21.110190.002405

Royle, N. J., Smiseth, P. T., \& Kolliker, M. (2012). The evolution of parental care. Oxford, UK: Oxford University Press.

Sato, T. (1986). A brood parasitic catfish of mouthbrooding cichlid fishes in Lake Tanganyka. Nature, 323, 58-59.

Semel, B., \& Sherman, P. W. (2001). Intraspecific parasitism and nest-site competition in wood ducks. Animal Behaviour, 61, 787-803. https://doi.org/10.1006/anbe.2000.1657

Sylvain, F. É., \& Derome, N. (2017). Vertically and horizontally transmitted microbial symbionts shape the gut microbiota ontogenesis of a skin-mucus feeding discus fish progeny. Scientific Reports, 7(1), 1-14. https://doi.org/10.1038/s41598-01705662-w

Taborsky, M. (2001). The evolution of bourgeois, parasitic, and cooperative reproductive behaviors in fishes. Journal of Heredity, 92(2), 100-110.

https://doi.org/10.1093/jhered/92.2.100

Thresher, R. (1985a). Brood-directed parental aggression and early brood loss in the coral reef fish, Acanthochromis polyacanthus (Pomacentridae). Animal Behaviour, 33(3), 897-907. https://doi.org/10.1016/S0003-3472(85)80024-5

Thresher, R. E. (1985b). Distribution, abundance, and reproductive success in the coral reef fish Acanthochromis polyacanthus. Ecology, 1985, 1139-1150.

https://doi.org/10.2307/1939166 
Trivers, R. (1972). Parental investment and sexual selection. In B. Campbell (Ed.), Sexual selection and the descent of man (1871-1971) (pp. 136-179). Chicago, IL: Aldine.

Wang, J. (2004). Sibship reconstruction from genetic data with typing errors. Genetics, 166(4), 1963-1979. https://doi.org/10.1534/genetics.166.4.1963

Ward, R. D., Zemlak, T. S., Innes, B. H., Last, P. R., \& Hebert, P. D. N. (2005). DNA barcoding Australia's fish species. Philosophical Transactions of the Royal Society of London. Series B, Biological Sciences, 360(1462), 1847- 1857. https://doi.org/10.1098/rstb.2005.1716

Wellington, G. M., \& Victor, B. C. (1989). Planktonic larval duration of one hundred species of Pacific and Atlantic damselfishes (Pomacentridae). Marine Biology, 101(4), 557-567. https://doi.org/10.1007/BF005 41659

Williams, G. C. (1966). The costs of reproduction, and a refinement of Lack's principle. American Naturalist, 100(916), 687-690.

Wisenden, B. D. (1999). Alloparental care in fishes. Reviews in Fish Biology and Fisheries, 9, 45-70.

Wisenden, B. D., Keenleyside, M. H. A., Wisenden, B. D., \& Keenleyside, M. H. A. (1992). Intraspecific brood adoption in convict cichlids: A mutual benefit. Behavioral Ecology and Sociobiology, 31(4), 263-269.

Yom-Tov, Y., \& Geffen, E. (2006). Geographic variation in body size : The effects of ambient temperature and precipitation. Oecologia, 148(7), 213-218. https://doi.org/10.1007/s00442-006-0364-9

\section{Supporting information}

Additional supporting information may be found online in the Supporting Information section at the end of the article on the Wiley's website. 